\title{
Comunicação Comunitária no Sertão do São Francisco: entre a utopia e a 'seca'
}

Céres Santos ${ }^{1}$

\section{Resumo}

Este artigo analisa dados da pesquisa de extensão Comunicação Comunitária de Juazeiro e Sertão do São Francisco, desenvolvida em 2008 e 2009, pela Universidade do Estado da Bahia (UNEB), para identificar as emissoras comunitárias localizadas nas cidades do Sertão do São Francisco - Campo Alegre de Lourdes, Canudos, Casa Nova, Curaçá, Juazeiro, Pilão Arcado, Remanso, Sento Sé, Sobradinho e Uauá. A pesquisa - a primeira desse território baiano - identificou, em operação, sete rádios comunitárias em Frequência Modulada (FM) e quatro no sistema de alto-falante. Informações, como tipos de programação e gestão, participação popular e captação de recursos, apontam para as utopias do fazer Comunicação Comunitária no Brasil diante de uma legislação em descompasso com a realidade desse jeito popular de fazer comunicação.

Palavras chaves: Comunicação Comunitária; Gestão; Participação popular.

\section{Resumen}

Este artículo analiza los datos de la investigacion Extensión Comunicación Comunitaria Juazeiro y del interior de San Francisco, desarrollada en 2008 y 2009 em la Universidade do Estado da Bahia (UNEB), para identificar las estaciones de La comunidad en las ciudad es del interior de San Francisco - Campo Alegre Lourdes, Canudos, Casa Nova, Curaçá, Juazeiro, Pilão Arcado, Remanso, Sento Sé, Sobradinho y Uauá. La investigación - La primera del Estado de Bahia - identificado, em funcionamiento, siete comunidades de frecuencia modulada (FM) y cuatro por el sistema de altavoces. Informaciones como los tipos de programación y lagestión, la participación popular y recaudación de fondos confirman lãs utopías de hacer comunicación comunitária en Brasil delante de una leyfuera de sintonia com la realidad de esta forma popular de hacer comunicación.

Palabras clave: Comunicación Comunitaria; Gestión; La participación popular.

\section{ABSTRACT}

This article analyzes survey data Extension Community Communication Juazeiro and hinterland of San Francisco, developed in 2008 and 2009 from the State University of Bahia

\footnotetext{
${ }^{1}$ Mestre em Educação e Contemporaneidade pela Universidade do Estado da Bahia (UNEB); professora no curso de Comunicação Social - Jornalismo em Multimeios UNEB/JuazeirolBA. Jornalista, graduada pela Pontifícia Universidade Católica (PUC) do Rio Grande do Sul. Coordenou, de 2010 a 2013, o CEAFRO, programa do Centro de Estudos AfroOrientais (CEAO), da (UFBA). E-mail: cmssantos@uneb.br
} 
Revista ComSertões

(UNEB), to identify the community stations in the cities of the hinterland of San Francisco Campo Alegre de Lourdes, Canudos, Casa Nova, Curaçá, Juazeiro, Pilão Arcado, Remanso, Sento Sé, Sobradinho e Uauá. The research identified community radios in Frequency Modulation (FM) and speaker system doodle. Information, such as types of programming and management, popular participation and fundraising point to the utopias of making Community Communication in Brazil before a law out of step with the reality of this popular way of doing communication

Keywords: Community Communication; Management; Popular participation.

\section{Introdução}

Os dados divulgados e analisados nesse artigo fazem parte da pesquisa de extensão Comunicação Comunitária em Juazeiro e Sertão do São Francisco, desenvolvida nos anos de 2008 e $2009^{2}$, e se limitam às emissoras comunitárias no sistema FM, embora também tenham sido identificadas emissoras no sistema de alto-falantes. Das 10 cidades do Sertão do São Francisco, em uma, Campo Alegre de Lourdes, tivemos dificuldades em localizar pessoas ligadas a Comunicação Comunitária local, para aplicar questionários ou fazer entrevista. Por conta desse imprevisto, não conseguimos obter dados desse município. Logo, do total de nove cidades visitadas (o território tem 10 municípios), a equipe do projeto ${ }^{3}$ aplicou18 questionários e fez 19 entrevistas. Assim, foi possível identificar, em operação, sete rádios comunitárias (RadCom's) em FM e quatro no sistema de alto-falante.

Mas antes da apresentação e análise desses dados, optamos por percorrer o seguinte percurso, com o propósito de contextualizar as informações: definir o Sertão do São Francisco, a Comunicação Comunitária e fazer um breve panorama sobre a Legislação. Já recorrendo aos resultados desta pesquisa, mostraremos o perfil das emissoras comunitárias identificadas no Sertão do São Francisco em FM e, só então, faremos análises de várias dessas informações apuradas.

Ao traçar um breve perfil deste Território de Identidade (TI ${ }^{4}$ do Sertão do São Francisco, vamos constatar algumas das especificidades da Comunicação Comunitária nessa

\footnotetext{
${ }^{2}$ Em 2009 foi realizado, na UNEB, Campus DCH IIIJuazeiro, o seminário Encontro de Formação em Comunicação Comunitária, etapa Sertão do São Francisco que contou com representantes de todas as emissoras do território e com apoio da UNEB, UFBA, IRDEB/TVE, Agecom, UNICEF, Sinterp/BA, Moc e Cipó.

${ }^{3}$ A pesquisa foi coordenada pela professora Mestra Céres Santos e contou com a vice-coordenação da professora Verbena Mourão, e com o trabalho dos1as estudantes pesquisadores las Alinne Suanne Torres (voluntária), Érica Daiana da Costa Silva (bolsista), Karine Pereira, (bolsista), Laura de Oliveira (voluntária) e Marcos Vinicius Santana (bolsista).

${ }^{4}$ O Estado Baiano foi subdividido em 26 Territórios de Identidades (TI's).
} 
Revista ComSertões

região, a mais esquecida, discriminada e desvalorizada do país, sobrevivendo, ainda, sem um amplo e eficiente programa político e institucional de desenvolvimento e de convivência com o clima semi-árido.

De acordo com dados do Instituto Brasileiro de Geografia e Estatística (IBGE), de 2007, o Sertão do São Francisco faz parte do Sertão Brasileiro. Esse ocupa uma área de $969.584 .4 \mathrm{~km} 2$ e tem uma população de quase 21 milhões de habitantes - todo o Nordeste tem 51.534.406, sendo 44\% no meio rural - e 1.133 municípios $^{5}$.

Já os 10 municípios que compõem o Território Sertão do São Francisco - Campo Alegre de Lourdes, Canudos, Casa Nova, Curaçá, Juazeiro, Pilão Arcado, Remando, Sento Sé, Sobradinho e Uauá - estão localizados no Extremo Norte do Estado da Bahia, já na divisa com os estados do Piauí (a Oeste e ao Norte) e de Pernambuco (ao Norte), tendo o Rio São Francisco como marco divisório com este estado. Sendo assim, o rio é, de fato, um divisor de águas da região. Ela tem duas partes e, ainda, a barragem de Sobradinho.

A população do território é de quase 521 mil habitantes e, desse total, cerca de 36,12\% (178.664 pessoas), vivem na área rural. Na região estão 31.768 agricultores familiares e 2.371 famílias assentadas.

POPULAÇÃO DO SERTÃO DO SÃO FRANCISCO

\begin{tabular}{|l|c|}
\hline \multicolumn{1}{|c|}{ MUNICÍPIO } & POPULAÇÃO \\
\hline Juazeiro & 230.538 \\
\hline Casa Nova & 62.862 \\
\hline Remanso & 38.004 \\
\hline Sento Sé & 36.517 \\
\hline Pilão Arcado & 32.844 \\
\hline Curaçá & 32.449 \\
\hline Campo Alegre de Lourdes & 26.935 \\
\hline Uauá & 24.662 \\
\hline Sobradinho & 21.315 \\
\hline Canudos & 14.656 \\
\hline TOTAL & $\mathbf{5 2 0 . 7 8 2}$ \\
\hline
\end{tabular}

Fonte: IBGE, 2007

O território Sertão do São Francisco abrange uma área de 61.746 Km², assim distribuídos:

\footnotetext{
${ }^{5}$ O Brasil tem 5.564 municípios.
} 
Revista ComSertões

\begin{tabular}{|l|c|}
\multicolumn{2}{|c|}{ ÁREA DO SERTÃO DO SÃO FRANCISCO } \\
\hline MUNICÍPIO & KM2 \\
\hline Campo Alegre de Lourdes & 2766 \\
\hline Canudos, & 3000 \\
\hline Casa Nova & 9697 \\
\hline Curaçá & 6476 \\
\hline Juazeiro & 6415 \\
\hline Pilão Arcado & 11761 \\
\hline Remanso & 4712 \\
\hline Sento Sé & 12629 \\
\hline Sobradinho & 1328 \\
\hline Uauá & 2962 \\
\hline TOTAL & $\mathbf{6 1 . 7 4 6}$ \\
\hline
\end{tabular}

Fonte: IBGE, 2007

Também há registros de comunidades quilombolas e indígenas. Seu IDH médio é 0,64 $4^{6}$, mas, quando comparado com outras cidades do Estado da Bahia, com 415 municípios, ou do Brasil, com 5.564 municípios, a classificação cai. Senão, vejamos:

\section{IDH DO SERTÃO DO SÃO FRANCISCO}

\begin{tabular}{|l|c|c|}
\hline \multicolumn{1}{|c|}{ Município } & $\begin{array}{c}\text { Classificação } \\
\text { estadual }\end{array}$ & $\begin{array}{c}\text { Classificação } \\
\text { nacional }\end{array}$ \\
\hline Sobradinho & 37 & 3251 \\
\hline Juazeiro & 40 & 3266 \\
\hline Pilão Arcado & 407 & 5338 \\
\hline Curaçá & 192 & 4207 \\
\hline Uauá & 231 & 4377 \\
\hline Remanso & 236 & 4387 \\
\hline Casa Nova & 248 & 4469 \\
\hline Sento Sé & 288 & 4602 \\
\hline Canudos & 303 & 4677 \\
\hline Campo Alegre de Lourdes & 364 & 4966 \\
\hline
\end{tabular}

Dados da pesquisa, 2008

\footnotetext{
${ }^{6} \mathrm{O}$ IDH é uma medida geral que amplia a perspectiva sobre o desenvolvimento humano. O índice varia em uma escala de 0 a 1 . Quanto mais próximo de 1, mais elevado é o IDH do país ou cidade. O ranking divide os países em quatro categorias: nações com índice de desenvolvimento "muito elevado", "elevado", "médio" e "baixo". Segundo classificação do PNUD, municípios com índice variando de 0 a 0, 499 o IDH é muito baixo. De 0, 500 a 0,599, baixo. De 0,600 até, 0699, médio de 0,700 a 0,799 alto e muito alto de 0,800 a 1,000.
} 
Revista ComSertões

Se pegarmos apenas os IDH's do item Educação, veremos que a situação do Território é bastante preocupante:

\section{IDH DA EDUCAÇÃO NO TERRITÓRIO DO SERTÃO DO SÃO FRANCISCO}

\begin{tabular}{|l|c|c|}
\hline \multicolumn{1}{|c|}{ MUNICÍPIO } & IDH EDUCAÇÃO & CLASSIFICAÇÃO \\
\hline Pilão Arcado & 0,343 & MUITO BAIXO \\
\hline Campo Alegre de Lourdes & 0,430 & MUITO BAIXO \\
\hline Casa Nova & 0,435 & MUITO BAIXO \\
\hline Remanso & 0,451 & MUITO BAIXO \\
\hline Canudos & 0453 & MUITO BAIXO \\
\hline Curaçá & 0,463 & MUITO BAIXO \\
\hline Sento Sé & 0,480 & MUITO BAIXO \\
\hline Uauá & 0,463 & MUITO BAIXO \\
\hline Sobradinho & 0,555 & BAIXO \\
\hline Juazeiro & 0,594 & BAIXO \\
\hline
\end{tabular}

Fonte: IBGE, 2010. Atlas do Desenvolvimento Humano, PNUD 2013

O clima do território caracteriza-se por ter apenas duas estações: outono e verão, dois períodos secos anuais - um com longo déficit hídrico seguido de chuvas intermitentes e, outro, com seca curta seguido de chuvas torrenciais.

A passos ainda muito lentos, o antigo carro-pipa está sendo substituído por cisternas e implantação de políticas para o enfrentamento da seca e convivência com o semiárido. Mais do que o sol, o que mais castiga o sertanejo é a falta de políticas públicas que levem água, comida e cultura para a região. Ou seja, desenvolvimento.

Na proposta de convivência com o semiárido, procura-se não só valorizar a região, mas também buscar uma nova representação (midiática) na qual a caatinga deixe de ser um local de árvores secas, sem vida, para apresentar bioma diverso, muito rico quando comparado com outros biomas semelhantes, em termos de clima e solo.

Porém, a ausência do Estado e de uma política eficaz faz com que boa parte da população dependa do carro pipa para ter água, ao invés de cisternas, e que se desenvolvam ações de impacto negativo na caatinga, que é a exploração dos recursos, como a lenha, componente importante para a geração de energética regional, provocando danos à biodiversidade e já dando início a processos de desertificação.

É nesse contexto de especificidades e diversidades populacionais que, no final dos anos 90, do século XX, surgem as primeiras emissoras de Comunicação Comunitária que, na 
Revista ComSertões

maioria das cidades do Sertão do São Francisco, tornaram-se as únicas fontes locais de informação da população.

\title{
Novos rumos da Comunicação Comunitária
}

Entende-se por Comunicação Comunitária a comunicação feita pela população e, segundo Cicília Peruzzo (2006),

\begin{abstract}
A comunicação popular representa uma forma alternativa de comunicação e tem sua origem nos movimentos populares dos anos de 1970 e 1980, no Brasil e na América Latina como um todo. Ela não se caracteriza como um tipo qualquer de mídia, mas como um processo de comunicação que emerge da ação dos grupos populares. Essa ação tem caráter mobilizador coletivo na figura dos movimentos e organizações populares, que perpassa e é perpassada por canais próprios de comunicação (p. 2).
\end{abstract}

Observa-se que a Comunicação Comunitária carrega, de forma intrínseca, uma participação popular singular: o desejo de ser sujeito ativo na construção social tendo como combustível principal a cidadania, os direitos civis, políticos, sociais e coletivos, e, como foco, o acesso aos meios de comunicação.

As formas como esse desejo é transformado em objeto real, em abertura de novas rádios ou TVs comunitárias estão, constantemente, em mudança, o que tem provocado uma revisão, inclusive, nos conceitos de Comunicação Popular e Comunitária, uma vez que os constituídos no final dos anos 70 até o início desde século já não contemplam os novos arranjos que contam, por exemplo, com a força e poder das novas tecnologias de informação e comunicação (NTIC).

Uma outra mudança da atualidade diz respeito à própria concepção de participação popular. Nos dados da pesquisa ora em análise, observam-se perfis semelhantes aos conceitos difundidos quando do surgimento da Comunicação Popular ou Comunitária. Mas na sua teia, transporta novos arranjos que não podem ser desprezados e também precisam ser identificados e analisados, pois são novos ingredientes de um processo que não pára. Em algumas emissoras há uma adequação às novas práticas dos movimentos sociais, seja em termos de participação, seja em termos de gestão dessas emissoras.

Atenta a esses novos arranjos, Peruzzo (2006) vai destacar que o termo comunitário passou a identificar diferentes processos comunicacionais, promovidos no conjunto das ações 


\section{Revista ComSertões}

da Comunicação Popular ou Comunitária e, também, na comunicação comercial, quando essa amplia seu foco de participação no processo de produção e veiculação da notícia, abrindo espaços para o jornalismo cidadão, por exemplo.

Peruzzo (2006) salienta que a Comunicação Popular ou Comunitária, nos tempos atuais, mantém seu sentido político que lhe caracteriza, que é a forma de expressão de segmentos excluídos da população, "mas em processo de mobilização visando atingir seus interesses e suprir necessidades de sobrevivência e de participação política” (p.2).

Como observa Peruzzo (2006) e como constatamos na pesquisa, a prática da Comunicação Popular ou Comunitária mantém, na atualidade, práticas antigas que lhe caracterizaram e novas que precisam ser também observadas, como é a ideia de comunidade ou participação popular na construção de novas emissoras comunitárias. Sem essa readequação, qualquer análise de ações atuais nesse campo pode se tornar equivocada, já que, de fato, a Comunicação Comunitária não se sustenta, apenas nos conceitos formulados há 40 anos. O período de tempo, 40 anos, é pequeno para a história, mas muito significativo e repleto de novos fazeres populares. Sem essa adequação, corremos o risco de negligenciar e excluir novas expressões dessa construção social, a Comunicação Comunitária.

$\mathrm{Na}$ atualidade, a Comunicação Popular ou Comunitária mantém-se dentro dos ideais, por exemplo, destacados por Mário Kaplun, de que ela é libertadora, transformadora, na qual o povo é o principal protagonista. No entanto, os mecanismos, as estratégias de ação mudaram, assim como mudou a participação do Estado na concessão de outorgas de novas rádios comunitárias, mesmo que ele ainda se mantenha reticente e resistente nesse processo, oferecendo tratamento diferenciado e discriminatório, entre as concessões para emissoras comunitárias e comerciais, por exemplo.

Mas, a ideia da ação popular se mantém. Afinal, o Ministério das Comunicações (MC) ainda exige a constituição de uma associação popular para que ela formule o pedido de concessão de sinal. Superada essa etapa, o pedido passa por um funil de critérios estabelecidos pelo MC que pode levar vários anos até uma resposta positiva, ou não. É nesse processo que a população é levada a iniciar um debate sobre a Comunicação, no caso a Comunitária, e a desejar a democratização dos meios de comunicação, onde a sua participação é fundamental. Ora, se as organizações da sociedade civil passaram por mudanças significativas, como a Comunicação Popular e Comunitária se manteria à parte, vivendo de 


\section{Revista ComSertões}

processos comunicacionais que não mais atendem à realidade de demandas locais e globais? É inegável que aquela Comunicação Popular e Comunitária, difundida na América Latina em períodos de ditadura militar, foi impactada por novos momentos, como a democracia brasileira, onde a sociedade trilhou novos caminhos de luta e conquistas importantes, a partir dessas novas formas de luta.

Nesse debate, Rozinaldo Antonio Miani (2011) é contrário ao uso da expressão Comunicação Comunitária como sinônimo de Comunicação Popular. Segundo ele, essas expressões carregam significados históricos distintos que, ao serem associados, provocam distorções. Sendo assim, ele vai se apoiar nas ideias de Raquel Paiva, quando afirma que comunidade "tem aparecido como investida de um poder de resgate da solidariedade humana ou da organicidade social perdida" (p. 4), e de Ciro Marcondes Filho, para definir comunidade "como aquela forma de organização que reúne as pessoas e resgata a sociabilidade perdida" (p.5).

Mesmo nesse novo cenário de transmutações, até mesmo no campo conceitual, o exercício da cidadania e do fazer comunitário se mantém, porém com novos formatos e vozes. Afinal, a Comunicação Comunitária promoveu novas interfaces. Evoluiu do sistema de altofalante para a rádio FM, embora ainda se encontre o sistema mais tradicional no Sertão do São Francisco, uma das regiões mais pobres do país. A Comunicação Comunitária pulou do vídeo popular, aquele transmitido em praça pública, para a TV Comunitária, essa, em sistema de canal fechado. Do boletim feito no mimeógrafo da escola para os jornais impressos ou digitalizados.

Também se revelam de forma plural e singular as necessidades de cada comunidade, de cada emissora. Nesse movimento, a Comunicação Comunitária continua exigindo, para oxigenação e sobrevivência, a participação popular, a participação comunitária não mais em um embate ideológico, porém mais real, mais local, mais possível. Ou seja, esses movimentos se tornaram mais permeável e aglutinador de outras linguagens do construto social, como as manifestações culturais.

Não vamos aqui, tratar do modelo de desenvolvimento que o país adotou, porém precisamos rever a ideia de comunidade, como propõe Raquel Paiva (2007), considerando, por exemplo, o seu potencial contra-hegemônico na Comunicação Social, produzindo não só novas formas de linguagens, mas também uma estrutura mais integrada e polifônica entre os públicos produtores e consumidores de mensagens. Dante das características da Comunicação 
Revista ComSertões

Comunitária, a necessidade de promover uma comunicação alicerçada na participação se mantém. Mantendo-se, assim, a ideia de comunidade, mesmo em um processo de transmutação.

\section{Legislação}

Nesse artigo não vamos aprofundar o debate sobre a legislação das rádios comunitárias, apenas citar a lei que regulamenta a Comunicação Comunitária é de 1998, lei no 9.612, através do Decreto $\mathrm{n}^{\circ} 2.615$, também de 1998 . No seu artigo $1^{\circ}$, temos a definição de Serviço de Radiodifusão Comunitária sonora: opera em frequência modulada (FM) e em baixa potência e cobertura restrita (raio de $1 \mathrm{~km}$ ), só podendo ser outorgada a fundações e associações comunitárias, sem fins lucrativos, com sede na localidade de prestação do serviço.

Já o $4^{\circ}$ artigo especifica os princípios desse tipo de rádio, como por exemplo: dar oportunidade à difusão de ideias, elementos de cultura, tradições e hábitos sociais da comunidade; oferecer mecanismo à formação e integração da comunidade, estimulando o lazer, a cultura e o convívio social; prestar serviços de utilidade pública, integrando-se aos serviços de defesa civil, sempre que necessário; contribuir para o aperfeiçoamento profissional nas áreas de atuação dos jornalistas e radialistas, de conformidade com a legislação profissional vigente; permitir a capacitação dos cidadãos no exercício do direito de expressão da forma mais acessível possível.

Se, por um lado, a lei vem regulamentar uma atividade que, no Brasil, já era praticada há mais de 30 anos e promovido muitas prisões de comunicadoreslas populares, por outro, a legislação cria dificuldades, seja pelo seu alcance da emissora, seja pelos limites impostos para a captação de recursos para a viabilidade de uma emissora. Mais recentemente, em 2011, o Ministério das Comunicações publicou a Portaria 462\11, definindo a ideia de "apoio cultural" a essas emissoras. Pela Portaria, só é permitida a veiculação de uma mensagem institucional, nome, endereço físico e eletrônico e telefone do patrocinador e pró́bem-se anúncios de produtos, bens, serviços, promoções, preços, ofertas, condições de pagamento, ou quaisquer outras vantagens que promovam ola patrocinadorla.

Há algum tempo, ativistas do movimento de rádios comunitárias, em nível nacional, consideram a lei como um obstáculo à democratização da comunicação, reclamam da morosidade na concessão do serviço e do alcance de até $1 \mathrm{~km}$ para a transmissão, em ondas de 


\section{Revista ComSertões}

baixa potência de até $25 \mathrm{w}$, de um único canal para as emissoras comunitárias, punição caso a comunitária interfira na frequência da comercial, proibição de publicidade.

\section{Comunicação Comunitária no Sertão do São Francisco}

Após a aplicação de questionários e fazer entrevistas, identificamos sete rádios comunitárias (RadCom's) em FM e quatro no sistema de alto-falante no território, assim distribuídas:

TOTAL DE EMISSORAS EM FUNCIONAMENTO

\begin{tabular}{|c|c|c|}
\hline MUNICÍPIOS & RADIO COMUM. & SISTEMA DE ALTO-FALANTE \\
\hline \multicolumn{3}{|c|}{ CAMPO ALEGRE DE LOURDES } \\
\hline CANUDOS & Atividade FM & \\
\hline CASA NOVA & Casa Nova FM & \\
\hline CURAÇÁ & Curaçá FM & \\
\hline JUAZEIRO & Liberdade FM & $\begin{array}{l}\text { Rádio Cultural (Quidé) } \\
\text { Sica (Sistema de Com. da As. de Des. } \\
\text { Com. do Tabuleiro) } \\
\text { Sistema Comunitário (João Paulo II) }\end{array}$ \\
\hline PILÃO ARCADO & Tropical FM* & \\
\hline REMANSO & Zabelê FM & \\
\hline \multicolumn{3}{|l|}{ SENTO SÉ } \\
\hline SOBRADINHO & & Rádio de Paizinho \\
\hline UAUÁ & Luz do Sertão FM & \\
\hline
\end{tabular}

Dados da pesquisa, 2008

Quanto à tabulação dos dados, chamou-nos a atenção que a maioria, cinco das sete emissoras, encaminhou seus pedidos de funcionamento ao Ministério das Comunicações (MC) nos anos de 1998 e 1999. O dado, por si só, já demanda outra investigação: em qual contexto essas populações estavam vivenciando na área de comunicação, que as motivou a tomar a mesma iniciativa, de desejar ter em suas cidades uma emissora comunitária? Afinal, a procura pela concessão se deu no mesmo ano em que o Governo Brasileiro aprovou a Lei $\mathrm{n}^{\circ}$ 9.612/98, que rege esse tipo de radiodifusão. Nesse item, o que mais nos impactou foi identificar que a maioria das associações teve que esperar uma média de seis anos para receber outorga do $\mathrm{MC}$. 
ress

Revista ComSertões

\begin{tabular}{|l|c|c|c|c|}
\hline \multicolumn{1}{|c|}{ MUNICÍPIO } & EMISSORA & PEDIDO & OUTORGA & $\begin{array}{c}\text { TEMPO } \\
\text { DE } \\
\text { ESPERA }\end{array}$ \\
\hline Campo Alegre de Lourdes & & & & \\
\hline Canudos & Atividade FM 87.9 & 1998 & 2007 & 09 anos \\
\hline Casa Nova & Casa Nova FM 104,9 & 2004 & 2008 & 04 anos \\
\hline Curaçá & Curaçá FM 87.9 & 1998 & 2006 & 08 anos \\
\hline Juazeiro & Liberdade FM 87.9 & 1998 & 2002 & 04 anos \\
\hline Pilão Arcado & Tropical FM 87,9 & 1999 & 2006 & 07 anos \\
\hline Remanso & Zabelê FM 87.9 & 1998 & 2006 & 08 anos \\
\hline Sento Sé & Oasis FM* & $\mathbf{1 9 9 7}$ & $\mathbf{2 0 0 6}$ & $\mathbf{0 9}$ anos \\
\hline Sobradinho & São Francisco FM* & $\mathbf{1 9 9 8}$ & & \\
\hline Uauá & Luz do Sertão FM & 2003 & 2008 & 05 anos \\
\hline Dados da pesquisa, 2008 & \multicolumn{2}{|r|}{ *não está em operação }
\end{tabular}

Outro fato que destacamos foi com relação ao número de associações criadas com esse propósito, uma das exigências do MC:

\section{ASSOCIAÇÕES CRIADAS}

\begin{tabular}{|l|c|}
\hline \multicolumn{1}{|c|}{ MUNICÍPIOS } & ASSOC. CRIADAS \\
\hline CAMPO ALEGRE DE LOURDES & \\
\hline CANUDOS & 05 \\
\hline CASA NOVA & 07 \\
\hline CURAÇÁ & 03 \\
\hline JUAZEIRO & 10 \\
\hline PILÃO ARCADO & 03 \\
\hline REMANSO & 04 \\
\hline SENTO SÉ & 06 \\
\hline SOBRADINHO & 03 \\
\hline UAUÁ & 04 \\
\hline TOTAL & $\mathbf{4 5}$ \\
\hline
\end{tabular}

Dados da pesquisa, 2008

Os números, ao lado dos pedidos de novas RadCom's, sinalizam, possivelmente, para uma movimentação atípica da sociedade civil em torno da instalação de emissoras comunitárias. Em 2008, no território Sertão do São Francisco, existiam 50 pedidos registrados 


\section{Revista ComSertões}

no MC; desse total, sete rádios em operação, sendo cinco já com licenças definitivas; duas autorizadas; três cadastradas e aguardando habilitação, três pedidos em análise e 36 pedidos $\operatorname{arquivados}^{7}$.

Outro dado que chama atenção diz respeito ao modelo de gestão das emissoras comunitárias, em operação no ano de 2008. Seis das sete emissoras em funcionamento adotaram um modelo tradicional de presidência, com concentração do poder e de tomadas de decisão, mesmo sendo essa presidência formada por representantes de vários segmentos da sociedade civil organizada.

\section{MODELO DE GESTÃO}

\begin{tabular}{|l|l|l|}
\hline MUNICÍPIO & \multicolumn{1}{|c|}{ EMISSORA } & \multicolumn{1}{c|}{ GESTÃO } \\
\hline Canudos, & Atividade FM 87.9 & Presidência \\
\hline Casa Nova & Casa Nova FM 104,9 & Diretoria \\
\hline Curaçá & Curaçá FM 87.9 & Presidência \\
\hline Juazeiro & Liberdade FM 87.9 & Presidência \\
\hline Pilão Arcado & Tropical FM 87,9 & Presidência \\
\hline Remanso & Zabelê FM 87.9 & Presidência \\
\hline Uauá & Luz do Sertão FM 87.9 & Presidência \\
\hline
\end{tabular}

Dados da pesquisa, 2008

Outra informação, a participação popular na programação das emissoras comunitária, demonstra certa timidez nesse tipo de intervenção, embora as emissoras, na sua maioria, gozem de grande aceitação social. Uma das justificativas para isso é que elas são a única emissora radiofônica da cidade.

\section{PARTICIPAÇÃO POPULAR}

\begin{tabular}{|c|l|c|}
\hline EMISSORA & MUNICÍPIO & PARTICIPAÇÃO POPULAR \\
\hline Atividade FM 87.9 & Canudos, & Representação na direção da emissora. Carta e telefone \\
\hline Casa Nova FM 104,9 & Casa Nova & $\begin{array}{l}\text { Representação na direção da emissora. Programas próprios } \\
\text { de integrantes dos movimentos sociais. Programação com } \\
\text { temas sociais e educativos }\end{array}$ \\
\hline Curaçá FM 87.9 & Curaçá & $\begin{array}{c}\text { Representação na direção da emissora. Participação } \\
\text { diversificada. Programação focada na sociedade }\end{array}$ \\
\hline Liberdade FM 87.9 & Juazeiro & $\begin{array}{l}\text { Representação na direção da emissora. Pouca participação. } \\
\text { Cartas e telefonemas com pedidos musicais, avisos de } \\
\text { utilidade pública }\end{array}$ \\
\hline
\end{tabular}

\footnotetext{
${ }^{7}$ Dados do Ministério das Comunicações: http://www.mc.gov.br/radio-comunitaria - acesso em 20 de julho de
} 2009. 
ICSS

Revista ComSertões

\begin{tabular}{|c|l|c|}
\hline Tropical FM 87,9 & Pilão Arcado & $\begin{array}{c}\text { Representação a direção da emissora. Prioridade na } \\
\text { programação }\end{array}$ \\
\hline Zabelê FM 87.9 & Remanso & $\begin{array}{c}\text { Representação na direção da emissora. Programação } \\
\text { diversa, com programas de notícias produzidos por } \\
\text { entidades da sociedade civil }\end{array}$ \\
\hline Luz do Sertão FM 87.9 & Uauá & $\begin{array}{c}\text { Representação na direção da emissora. Programação } \\
\text { diversa, com programas de notícias produzidos por } \\
\text { entidades da sociedade civil }\end{array}$ \\
\hline
\end{tabular}

Dados da pesquisa. 2008

Observa-se, nesse item, que a participação popular tem variações de formas e intensidades. Em algumas emissoras, como a Liberdade FM (Juazeiro), e na Atividade FM (Canudos), a participação é mais tímida e, muitas vezes, limitada a pedidos de veiculação de música ou de algum aviso, colocando em risco uma das funções da Comunicação Comunitária. Em outras, como na Curaçá FM (Curaçá), Zabelê FM (Remanso) e Luz do Sertão (Uauá), a presença é bastante intensa. Além da participação na gestão da emissora, a sociedade participa com programas produzidos por entidades da sociedade civil, através de discussão de temas de interesse da população.

Mas, preocupa a incidência de programas religiosos veiculados nas emissoras comunitárias do Sertão do São Francisco:

PROGRAMAÇÃO RELIGIOSA

\begin{tabular}{|c|l|l|}
\hline EMISSORA & MUNICÍPIO & \multicolumn{1}{|c|}{ RELIGIÕES } \\
\hline Atividade FM 87.9 & Canudos, & Evangélica e Católica \\
\hline Casa Nova FM 104,9 & Casa Nova & Evangélica e Católica \\
\hline Curaçá FM 87.9 & Curaçá & Evangélica, Católica e Espírita \\
\hline Liberdade FM 87.9 & Juazeiro & Evangélica \\
\hline Tropical FM 87,9 & Pilão Arcado & Evangélica e Católica \\
\hline Zabelê FM 87.9 & Remanso & Evangélica e Católica \\
\hline Luz do Sertão FM 87.9 & Uauá & Evangélica e Católica \\
\hline
\end{tabular}

Dados da pesquisa, 2008

O tema é, na atualidade, na área da Comunicação Comunitária, um dos mais polêmicos, acirrando os ânimos entre os favoráveis e contrários à presença religiosa nas emissoras comunitárias em FM. Apesar das críticas procedentes em relação à lei que rege as rádios comunitárias, a de $n^{\circ}$ 9.612/98; ela é explicita, quando diz, nos artigos $4^{\circ}$ e $11^{\circ}$, que é proibido "o proselitismo de qualquer natureza na programação das emissoras de radiodifusão comunitária". Ou seja, é vedada a pregação, a catequese, a difusão de cultos etc. Diz, ainda, 


\section{Revista ComSertões}

que a emissora não pode ser dirigida ou ter alguma relação de subalternidade com instituições religiosas.

Contudo, esse dado observado na pesquisa não é nosso principal foco de análise. Acreditamos que o tema, por sua complexidade, deve ser tratado em outro espaço. No entanto, não podemos deixar de notar que a própria criação e trajetória das RadCom's na América Latina contou com apoio direto da Igreja Católica, apoio esse que se mantém até hoje, ao ponto dela ter criado a Associação Nacional Católica de RadCom's (Ancarc). Por outro lado, não podemos desmerecer que o binômio religiões evangélicas e poder tem contribuído para a proliferação de emissoras políticas concedidas para igrejas ou associações religiosas, o que também é proibido por lei.

Agora, o fato é presente: todas as emissoras comunitárias em FM do Sertão do São Francisco cedem espaço da grade de programação para religiosos de dois segmentos: Católico e Evangélico. A Curaçá FM amplia, para outra religião, o espiritismo. A questão é tão complexa que já tramita na Câmara dos Deputados o projeto de Lei 1665\03, do deputado Wladimir Costa (PMDB-PA), estabelecendo regras para o patrocínio e veiculação de programas religiosos nas rádios comunitárias, alterando, assim, a lei atual.

Outro dado que a pesquisa apurou e que também é nevrálgico, diz respeito à existência do "apoio cultural", em todas as emissoras listadas. Porém, nem todas estão em conformidade com a Portaria 462\11, do MC. Ela define essa forma de anúncio e diz que, em emissoras comunitárias, só é permitido veiculação de uma mensagem institucional, nome, endereço físico e eletrônico e telefone do patrocinador, e proíbe anúncios de produtos, bens, serviços, promoções, preços, ofertas, condições de pagamento, ou quaisquer outras vantagens que promovam a pessoa jurídica patrocinadora. Os apoios se restringem aos anunciantes abrangidos pelo raio de um quilômetro da antena da emissora, não podendo receber, na maioria dos casos, apoio cultural da administração pública.

Não menos preocupantes são as informações sobre formação da equipe. Apesar de todas as equipes terem recebido alguma formação técnica, todas se queixam da falta de uma formação direcionada, mais completa e profissional, que trate, por exemplo, do papel de uma rádio comunitária. Na Atividade FM 87.9 (Canudos $\backslash \mathrm{BA}$ ), por exemplo, de uma equipe inicial com 11 pessoas, apenas três tiveram formação através de oficinas ministradas pelo Sindicato de Locutores da Bahia, específica para comunicadoreslas comunitárioslas. 


\section{Revista ComSertões}

Na Casa Nova FM 104,9 (Casa NovalBA), toda a equipe recebeu formação técnica ministrada por uma escola técnica de São Paulo, que oferecia curso profissionalizante à distância, com 90 dias de duração. Na época da criação da Curaçá FM 87.9 (CuraçálBA), a equipe recebeu ajuda de um técnico para a manutenção dos equipamentos e a capacitação foi feita por professores do Departamento de Ciências Humanas III (DCH III), da Universidade do Estado da Bahia (UNEB), Campus de Juazeiro.

Na Zabelê FM 87.9 (RemansolBA), a equipe recebeu capacitação do Setor Diocesano de Comunicação e Audiovisual da Diocese de Juazeiro (SEDICA), que ofereceu treinamento de gravação de áudio, preparação e formação de programas e aproveitamento da voz. Cada curso teve uma carga horária de 14 horas. $\mathrm{Na}$ época da pesquisa, poucas pessoas sabiam operar os equipamentos e editar os programas. A equipe da Luz do Sertão FM 87.9 recebeu formação técnica do SEDICA, para atuar com a rádio comunitária. A capacitação foi de técnicas de locução e apresentação de programas de rádio, com carga horária de 16 horas.

\section{Considerações Finais}

O mapeamento realizado pela pesquisa Comunicação Comunitária de Juazeiro e Sertão do São Francisco, desenvolvida em 2008 e 2009, permitiu o enriquecimento do debate em torno da Comunicação Comunitária, pois trouxe à tona uma realidade permeada de semelhanças com as demais emissoras existentes no país: dificuldades para a formação e reconhecimento profissional doslas comunicadoreslas populares, distorções no entendimento e prática de participação popular nas RadCom's, assim como no modelo de gestão que se diferencie de tipos convencionais hierarquizados, pouco democráticos e centralizadores; contexto esse que precisa receber interferências, inclusive, institucionais voltadas para a promoção desse tipo de fazer comunicação.

Questões cruciais para a Comunicação Comunitária precisam ser revistas, como é o caso da participação popular que, na medida do possível, deve ser estimulada, pois esse é um dos importantes diferenciais da comunicação comercial. Essa participação popular não pode ficar resumida aos pedidos musicais, feitos por telefone. As RadCom's não podem evitar as falas populares nas suas grandes de programação. Nem mesmo a Anatel, ao cumprir a Lei 9.612/98, pode continuar sua tentativa de emudecer a voz popular. 


\section{Revista ComSertões}

A pesquisa também evidencia problemas de sustentabilidade econômica dessas emissoras, assim como dificuldades no pagamento das equipes que nelas trabalham. Essa falta de recursos resulta, em muitos momentos, da colisão das RadCom's com as leis. Também preocupa a insistente presença de religiões nas grades de programação das emissoras comunitárias do Sertão do São Francisco. Esse tipo de coronelismo, assim como o político, é uma questão que interfere no fazer Comunicação Comunitária, nos processos comunicacionais democráticos. Redundante, porém necessário, destacar a urgência na revisão da Lei 9.612/98.

A pesquisa também coloca na pauta a necessidade da sua atualização, uma vez que o segmento tem passado por novas interferências, como é o caso das novas tecnologias de informação e comunicação (NTIC) e a ampliação do número de rádios comunitárias na web. Acreditamos que a continuidade da pesquisa propiciará uma nova intervenção do DCH III da UNEB na Comunicação Comunitária do Sertão do São Francisco, a partir das necessidades já apontadas nos dados, levantados, principalmente em relação à formação dosłas comunicadoreslas populares.

Apesar da pesquisa mostrar histórias e contextos ainda adversos, nota-se, por outro lado, que ela vislumbra um dos desejos mais significativos da humanidade: o da comunicação como um direito humano. Foi esse desejo que moveu pessoas de uma das regiões mais pobres do país para se comunicarem, dialogarem sobre questões de interesse local e global.

\section{REFERENCIAS}

Atlas Brasil. Disponível em: http://www.atlasbrasil.org.br/2013/. Acesso em 26 de março de 2014

COMSERTOES. Revista de Comunicação e Cultura do Semiárido. UNEB, DCHIII, NUPE, EDUNEB, Juazeiro\BA, Volume1, no 1, julholdezembro de 2013.

DUARTE, Edson. Liberdade de expressão das rádios comunitárias. Brasília: Gabinete do deputado federal Edson Duarte (PV/BA), 2004.

LORENZON, Adriane. Poder local no ar: municipalização das RadCom's e fortalecimento de esferas públicas locais no Brasil. Brasília: Abravídeo, 2009.

LUZ, Dioclécio. Rádios Comunitárias: trilha apaixonada e bem-humorada do que é e de como fazer RadCom's na intenção de mudar o mundo. 2. Ed. Brasília: Produção Independente, 2004. 
MIANI, Rozinaldo Antonio. Os pressupostos teóricos da comunicação comunitária e sua condição de alternativa política ao monopólio midiático. Disponível em:

http://www.seer.ufrgs.br/intexto/article/viewFile/16547/14492. Acesso em 02 de abril de 2014.

Ministério das Comunicações. Disponível em: http://www.mc.gov.br/radio-comunitaria. Acesso em 20 de julho de 2009.

NUNES, Vidal Márcia. As RadCom's nas campanhas eleitorais: exercício da cidadania ou instrumentalização (1998-2000). Disponível em: http://www.scielo.br/pdf/rsocp/n22/n22a06.pdf - Acesso em 01 abril de 2014.

e ALMEIDA, Fernando F. de. (Org.). Mídia comunitária, liberdade de comunicação e desenvolvimento. In: Comunicação para cidadania. São Paulo: INTERCOM; Salvador: UNEB; 2003. p. 245 - 260.

PAIVA, Raquel. O retorno da Comunidade - os novos caminhos do social. Rio de Janeiro. Mauad X, 2007.

A comunicação como projeto social. Disponível em: http://leccufrj.files.wordpress.com/2011/02/paiva_comunicacao-como-projeto-social.pdf. Acesso em 02 de abril de 2014

PERUZZO, Cicilia M. K. Comunicação nos movimentos populares: a participação da construção da cidadania. Editora Petrópolis: Vozes, 2004.

Rádio comunitária, educomunicação e desenvolvimento local. Net, Rio de Janeiro, 2007. P. 69- 94. Disponível em: <http://www.ciciliaperuzzo.pro.br/artigos/radio_comunitaria_educomunicacao_e_desenvolvi mento_local.pdf>. Acesso em: 07 julho 2009.

Comunicação Comunitária e Educação para a Cidadania. Disponível em: http://www.usp.br/nce/wcp/arq/textos/48.pdf. Acesso em 29 de março de 2014

TEIXEIRA, Elenaldo. O local e o global: limites e desafios da participação cidadã. São Paulo: Cortez; Recife: EQUIP; Salvador: UFBA, 2001.

UNIVERSIDADE DO ESTADO DA BAHIA (UNEB). Relatório da pesquisa de extensão Comunicação Comunitária em Juazeiro e Sertão do São Francisco. DCH III, Juazeiro, 2014.

VOLPATO, Marcelo de Oliveira. A religião nas rádios comunitárias "Gospel FM" e "Jornal FM". Disponível em: http://www.usp.br/alterjor/ojs/index.php/alterjor/article/view/aj1-a5/pdf_17. Acesso em: 29 de março de 2014. 